\title{
Experiment on Seepage Property and Sand Inrush Criterion for Granular Rock Mass
}

\author{
Kai Zhang, ${ }^{1,2}$ Boyang Zhang, ${ }^{3}$ Jiangfeng Liu, ${ }^{1,2}$ Dan Ma, ${ }^{4}$ and Haibo Bai ${ }^{1,2}$ \\ ${ }^{1}$ State Key Laboratory for Geomechanics and Deep Underground Engineering, China University of Mining \& Technology, \\ Xuzhou 221116, China \\ ${ }^{2}$ School of Mechanics and Civil Engineering, China University of Mining \& Technology, Xuzhou 221116, China \\ ${ }^{3}$ School of Civil Engineering, Henan Polytechnic University, Jiaozuo 454000, China \\ ${ }^{4}$ School of Resources \& Safety Engineering, Central South University, Changsha 410083, China
}

Correspondence should be addressed to Boyang Zhang; zhangboyang@hpu.edu.cn

Received 29 June 2017; Revised 25 September 2017; Accepted 15 October 2017; Published 2 November 2017

Academic Editor: Wei Wu

Copyright (C) 2017 Kai Zhang et al. This is an open access article distributed under the Creative Commons Attribution License, which permits unrestricted use, distribution, and reproduction in any medium, provided the original work is properly cited.

\begin{abstract}
Water and sand inrush is one of the most serious threats in some shallow coal mines in China. In order to understand the process of sand inrush, experiments were performed to obtain the criterion for sand inrush. First, seepage tests were carried out to study the hydraulic properties of granular sandstone. The results indicate that seepage velocity has a linear relation with the porosity and particle-size distribution parameter. Then, sand inrush tests were conducted to investigate the critical conditions for sand inrush occurrence. It is determined that the sand inrush zone can be clearly distinguished based on the values of porosity and particle-size distribution parameter. Additionally, sand inrush tended to happen in the conditions of high porosity, high seepage velocity, and large particle-size distribution parameter. Further, general principles for preventing the water and sand inrush were proposed, such as reducing the porosity, improving the pore structure, and decreasing the seepage velocity. The proposed principles have been successfully used in situ to control the water and sand inrush.
\end{abstract}

\section{Introduction}

The coal field in Shaanxi province is now one of the major coal bases in China. The typical characteristics of the coal mines in this area are the shallow mining depth, aeolian sand bed near the ground surface, and thick coal seams. Compared with the coal mines with deep mining depth, the overburden strata movement and the distribution of the mining induced fractures are quite different in the coal mines in Shaanxi coal field (see Figure 1). When mining in deep depth (Figure 1(a)), the overburden strata over the goaf can be stable due to the effect of pressured arch, and the height of the mining induced fractures is usually 15 to 20 times of the height of mined coal seam [1]. However, when the mining depth is shallow (Figure 1(b)), the mining induced fractures may go through the rock layers to the sand bed, or even to the ground surface (Figure 2). In this situation, water and sand may move through the fractures and granular rock mass to the goaf and affect mining safety. The statistics shows that water and sand movement significantly affects 285 coal mines (with estimated reserves exceeding 100 billion tons) in China during extracting the coal seams which are covered by the unconsolidated Cenozoic alluvium [2]. For example, a water and sand inrush accident happened in Halagou coal mine in 2010 [3]. The entire longwall mining face and part of the roadways were filled with sand. Around the ground surface, a cone with a height of $12 \mathrm{~m}$ and a maximum diameter of $47 \mathrm{~m}$ was formed. The mining activity had to be stopped for days until the sand was cleared.

There is another pathway for water and sand inrush in this area, which is via the geological boreholes drilled from the ground surface. As the boreholes were drilled through the sand bed and aquifer, if the boreholes are not sealed properly, water and sand inrush may occur. For example, a mixture of water and sand rushed into the roadway in Longde coal mine [4] when a borehole was drilled from 


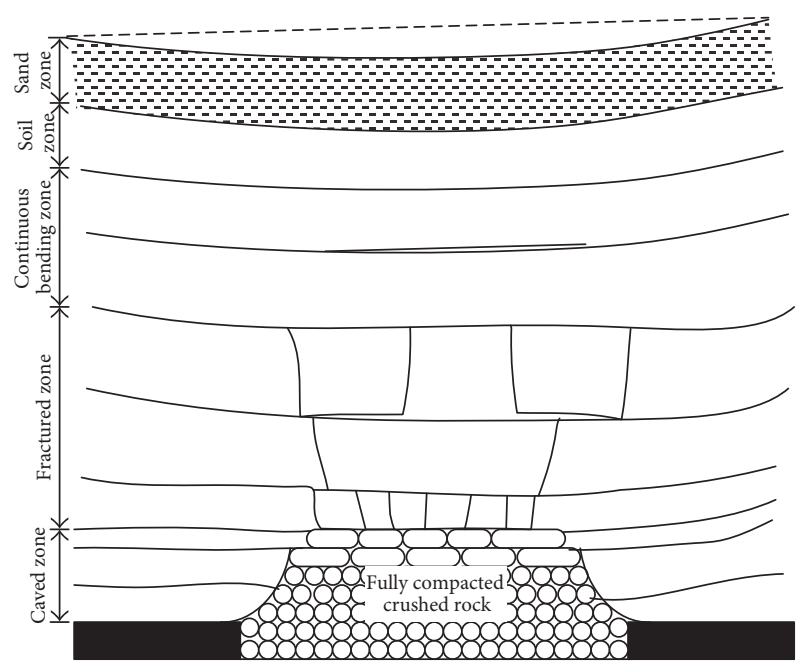

(a)

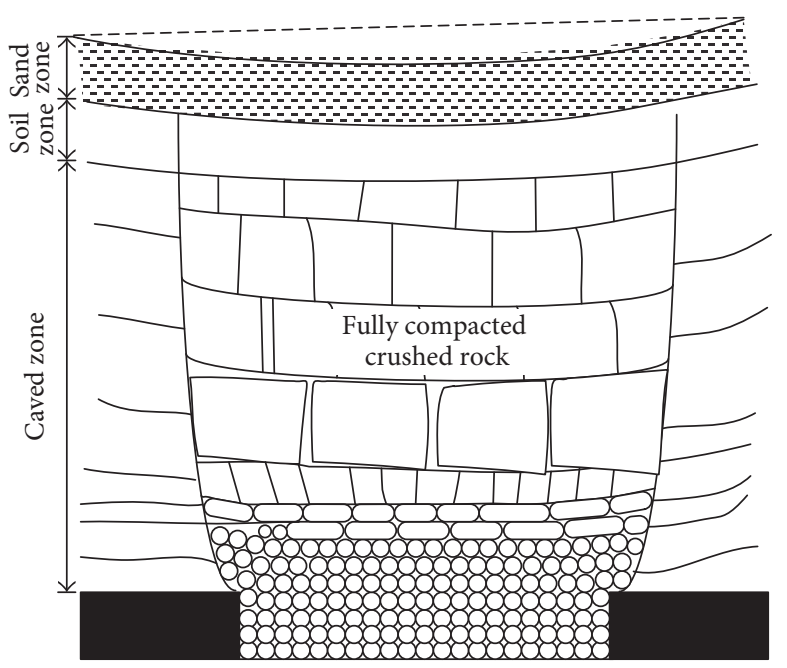

(b)

FIGURE 1: Overburden strata movement above a longwall panel: (a) thin coal seam with deep mining depth [16]; (b) thick coal seam with shallow mining depth.

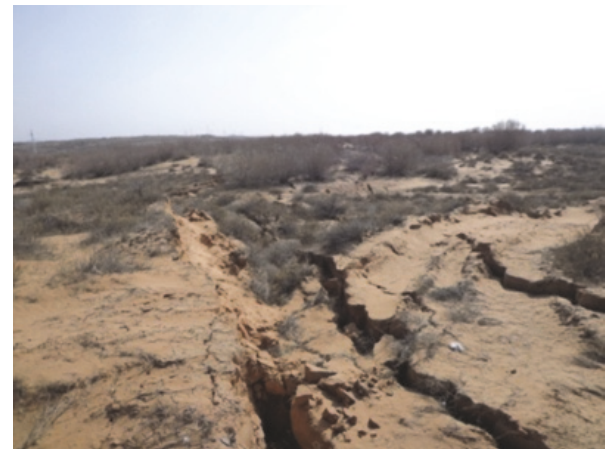

FIGURE 2: Mining induced fractures around the ground surface.

the ground to the roadway (Figure 3). As a result, many underground equipment and vehicles were buried, which led to an economic loss of tens of millions of dollars.

In order to prevent water and sand inrush problems, a number of researches were performed. These researches mainly focused on the physical and mechanical properties of water and sand mixture $[5,6]$ and the flow of the mixture in fractures [7-9]. It is found that the gradient of water pressure is the main factor for sand inrush. Some researchers investigated the permeability of sedimentary basins for water and sand movement and proposed some models to determine the permeability based on the porosity $[10,11]$. Since there are always broken rock layers and granular rock mass around the goaf, the permeability of this area plays an important role in controlling the water and sand movement. In recent years, a great deal of effort has been put to investigate the permeability of the granular rock mass [12-15]. The main outcome is that the permeability of granular rock mass is sensitive to the stress condition and the granular composition, and its value varies due to the loss of small particles during seepage.

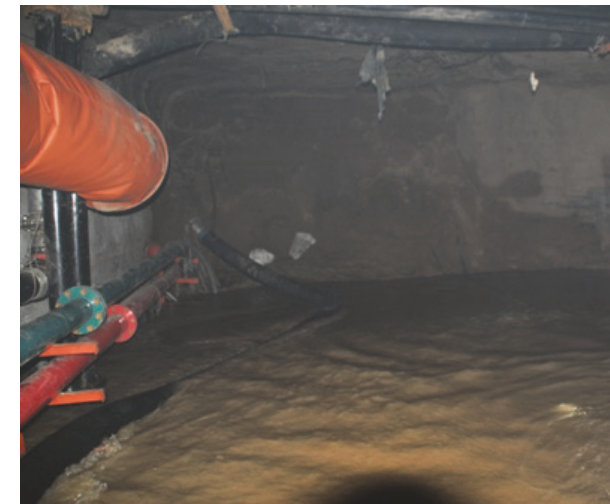

Figure 3: Water and sand inrush in Longde coal mine.

Since water and sand inrush problems mostly occur in the granular rock mass during coal mining and the accidents were always controlled by improving the conditions of granular rock mass, it is essential to investigate the characteristic of water and sand movement in the granular rock mass. Although the permeability characteristics of the granular rock mass have been widely studied, there is still some confusion whether the sand inrush will happen at specific states of the granular rock mass. This study aims to reveal the conditions for sand inrush occurrence in granular rock mass by the laboratory experiments. We first carried out the seepage tests to study the hydraulic properties of the granular sandstone (without sand) under different granular compositions and porosities. Based on the results, an equation was proposed to calculate the seepage velocity. Then, the sand inrush tests were performed, and a criterion for sand inrush was established. Based on the experimental results, the principles for preventing water and sand inrush problems were therefore proposed. 


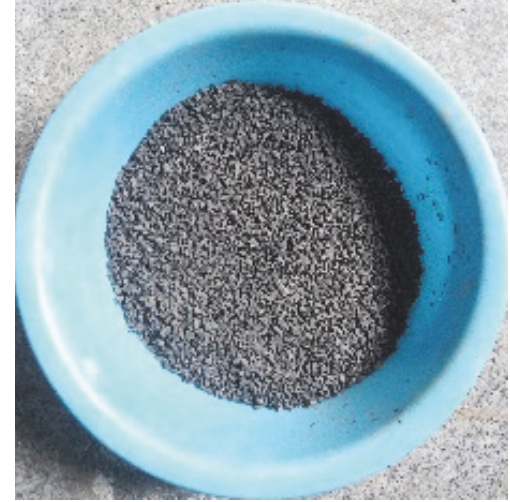

(a)

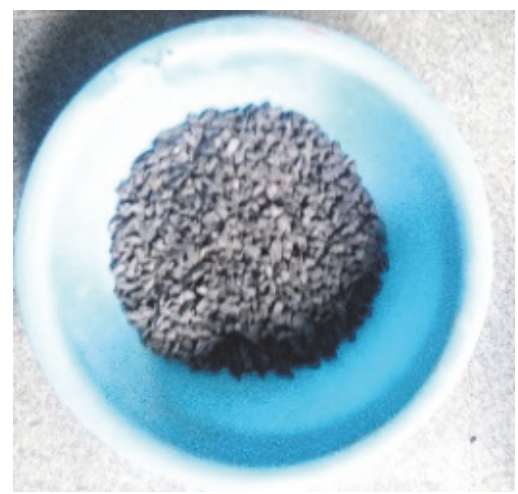

(d)

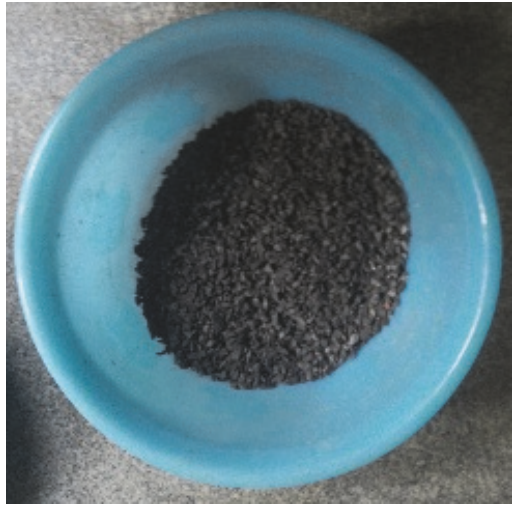

(b)

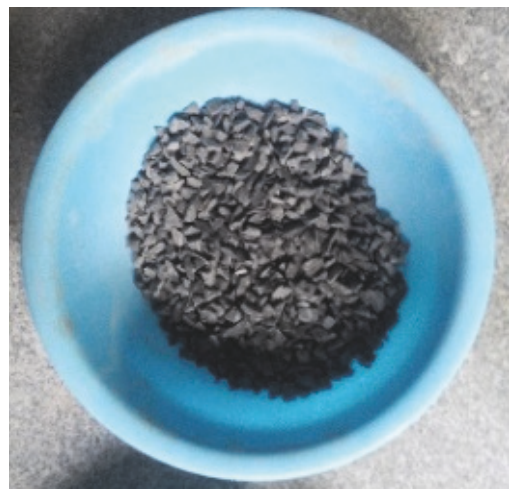

(e)

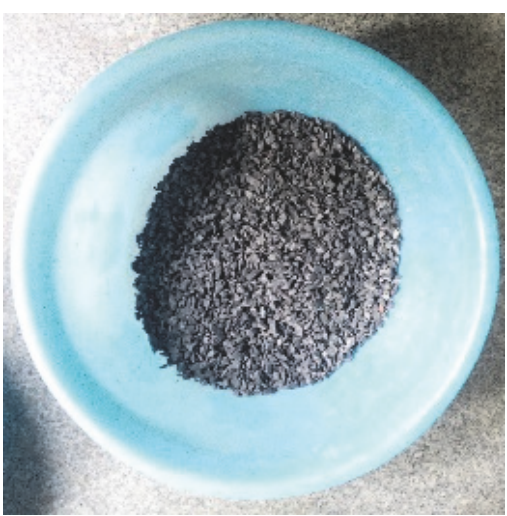

(c)

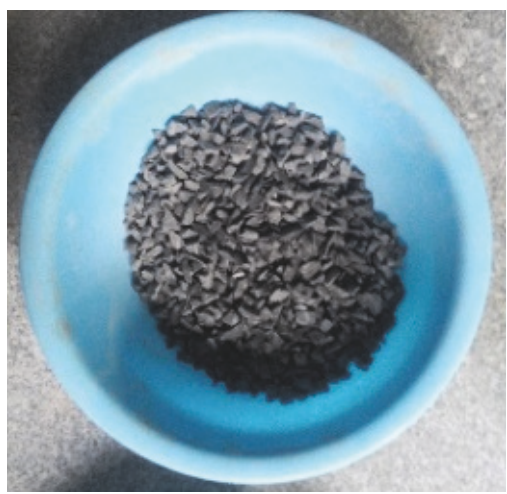

(f)

Figure 4: Rock particles with different size ranges: (a) 2.5 to $5.0 \mathrm{~mm}$; (b) 5.0 to $8.0 \mathrm{~mm}$; (c) 8.0 to $10.0 \mathrm{~mm}$; (d) 10.0 to $12.0 \mathrm{~mm}$; (e) 12.0 to $15.0 \mathrm{~mm}$; (f) 15.0 to $20.0 \mathrm{~mm}$.

\section{Experimental Materials and Testing Methods}

2.1. Experimental Materials. Sandstone samples were chosen in this study, which were taken from Longde coal mine in Shaanxi Province of China. The rock samples were crushed into particles with a hammer. The particles were separated into six groups using separation screens according to their sizes (ranging from $2.5 \mathrm{~mm}$ to $20 \mathrm{~mm}$ ), as shown in Table 1 and Figure 4.

To simulate the broken rock mass induced by coal mining, we assemble the rock particles with specific particle-size distributions. In order to express the particle-size distribution, Talbot formula [17] was adopted, which is a continuous gradation theory developed from Fuller formula [18]. The Talbot formula has been used as a simple and effective method to describe the composition of granular rock mass [15]. According to Talbot formula, the mass ratio of the particles with a specific size range can be expressed as

$$
p_{i}= \begin{cases}{\left[\left(\frac{d_{i+1}}{D}\right)^{n}-\left(\frac{d_{i}}{D}\right)^{n}\right] \times 100 \%,} & i>1, \\ \left(\frac{d_{i}}{D}\right)^{n} \times 100 \%, & i=1,\end{cases}
$$

where $i$ is the size range number of the rock particles (see Table 1$), D$ is the largest particle size, $d_{i}$ is the largest particle size in range $i, p_{i}$ is the mass ratio of the particles in range $i$, and $n$ is the Talbot power exponent, which is referred to as size distribution parameter in the following.

To prepare different granular rock mass specimens, various size distribution parameters were selected (e.g., ranging from 0.5 to 1.5 ). The details are given in Table 1 , and the corresponding particle-size distribution curves are shown in Figure 5. The ratio of large particles increased as the size distribution parameter $n$ increased. The mass of particles with different sizes are shown in Figure 6. In the figure, the horizontal axis is the average particle size in a particle-size range. It can be determined that the composition of the rock mass changed gradually with the variation of the parameter $n$.

The sand used in the experiment was aeolian sand (Figure 7), which was taken from Yulin in the north of Shaanxi Province, China. The coring site is approximately $20 \mathrm{~km}$ from the Longde coal mine. The particle-size distribution of the sand is listed in Table 2. The density of the aeolian sand is $1174 \mathrm{~kg} / \mathrm{m}^{3}$, and the natural porosity is approximately $54 \%$.

2.2. Testing System. To conduct the experiments, we developed a seepage testing apparatus for granular rock mass. The detailed design of the seepage testing apparatus is shown in Figure 8. In the tests, the premixed granular rock mass was put into the cylinder cell, and the aeolian sand was put in the tank over the granular rock mass. Then, the piston was 
TABLE 1: Mass ratio of rock particles with various size ranges under different size distribution parameters.

\begin{tabular}{|c|c|c|c|c|c|c|}
\hline \multirow{2}{*}{$i$} & \multirow{2}{*}{ Size range $(\mathrm{mm})$} & \multicolumn{5}{|c|}{ Size distribution parameter $n$} \\
\hline & & 0.50 & 0.75 & 1.00 & 1.25 & 1.5 \\
\hline 1 & $2.5 \sim 5.0$ & $50.0 \%$ & $35.4 \%$ & $25.0 \%$ & $17.7 \%$ & $14.4 \%$ \\
\hline 2 & $5.0 \sim 8.0$ & $13.2 \%$ & $14.9 \%$ & $15.0 \%$ & $14.1 \%$ & $13.4 \%$ \\
\hline 3 & $8.0 \sim 10.0$ & $7.5 \%$ & $9.2 \%$ & $10.0 \%$ & $10.2 \%$ & $10.2 \%$ \\
\hline 4 & $10.0 \sim 12.0$ & $6.7 \%$ & $8.7 \%$ & $10.0 \%$ & $10.8 \%$ & $11.0 \%$ \\
\hline 5 & $12.0 \sim 15.0$ & $9.1 \%$ & $12.4 \%$ & $15.0 \%$ & $17.0 \%$ & $17.9 \%$ \\
\hline 6 & $15.0 \sim 20.0$ & $13.4 \%$ & $19.4 \%$ & $25.0 \%$ & $30.2 \%$ & $33.2 \%$ \\
\hline
\end{tabular}

TABLE 2: Particle-size distribution of the aeolian sand.

\begin{tabular}{lcc}
\hline Particle diameter $(\mathrm{mm})$ & Ratio $(\%)$ & Average size $(\mathrm{mm})$ \\
\hline$<0.10$ & 5 & \\
$0.10 \sim 0.25$ & 45 & 0.25 \\
$0.25 \sim 0.50$ & 45 & \\
$0.50 \sim 1.00$ & 5 & \\
\hline
\end{tabular}

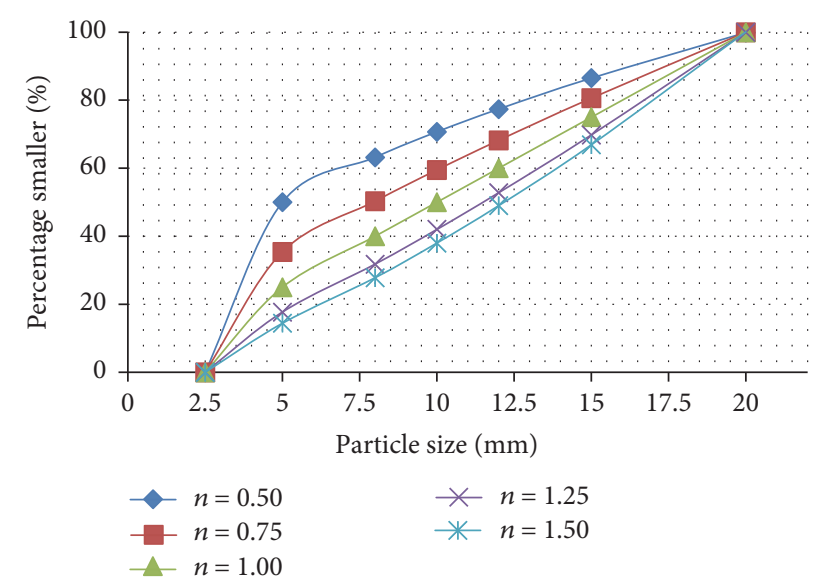

FIGURE 5: Particle-size distribution curves of the granular rock mass.

installed in the cylinder cell on the sand tank. In the piston, there was a pipeline for the water inlet.

As a preliminary attempt, we did not vary the water pressure in the present experiments. Water was injected using a pump from the upstream sample side (i.e., the top surface of the sample), with $0.5 \mathrm{MPa}$ of water pressure and a downstream pressure of zero. As a result, the water pressure gradient in the rock sample is approximately $3 \times 10^{-3} \mathrm{MPa} / \mathrm{mm}$. According to the previous research [19], the seepage in the rock mass followed Darcy's law under this applied pressure gradient.

MTS816 servo-control testing machine was used to apply load to the seepage testing apparatus. The layout of the testing system is shown in Figure 9. During the tests, the seepage testing apparatus was loaded in the axial direction through the piston, and the granular rock mass was compressed with lateral constraint.

2.3. Testing Procedure. Two kinds of tests were designed, that is, seepage test and sand inrush test. When sand was put over

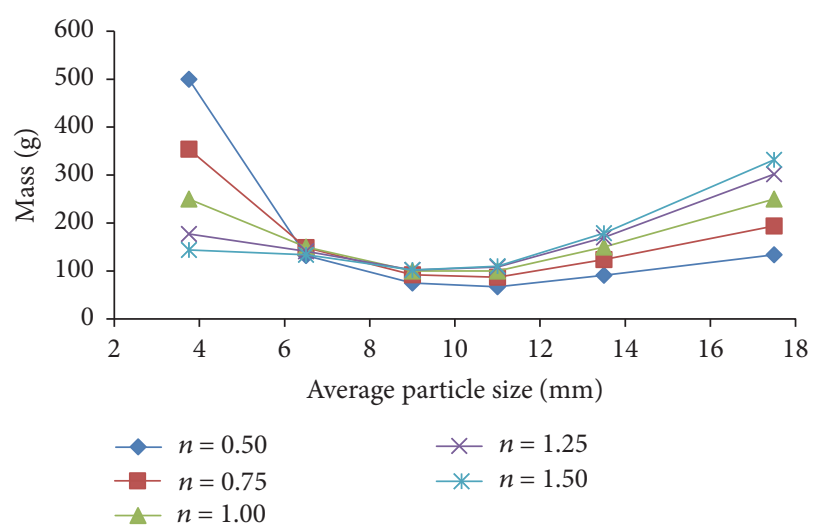

FIGURE 6: Mass of particles with different sizes in $1 \mathrm{~kg}$ granular rock mass.

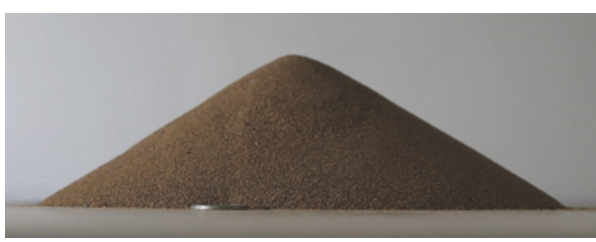

Figure 7: Aeolian sand sample.

the granular rock mass, the outlet fluid would be a mixture of water and sand. Then, the density of the outlet fluid may vary constantly and make it difficult to determine the permeability of the rock mass. So, in the seepage test, the sand is absent.

2.3.1. Seepage Test of Granular Rock Mass without Sand. These tests were conducted to investigate the water permeability of the granular rock mass. 15 sets of tests were carried out (Table 3). Each set of test was performed three times. In Table 3 , the parameter $h$ is the height of the specimen, with an initial value of $150 \mathrm{~mm}$. In order to simulate the various values of the porosity of the in situ granular rock mass, the specimen was compressed to a specific height. A typical compressive curve of the specimen is shown in Figure 10. The stiffness of the specimen increased with the increase in compressive displacement, which was typical for granular rock mass. During the compression, the particles would be broken and the particle-size distribution changed. However, after checking the compressed specimen, there were only a few particles with sharp corners broken. The displacement was 


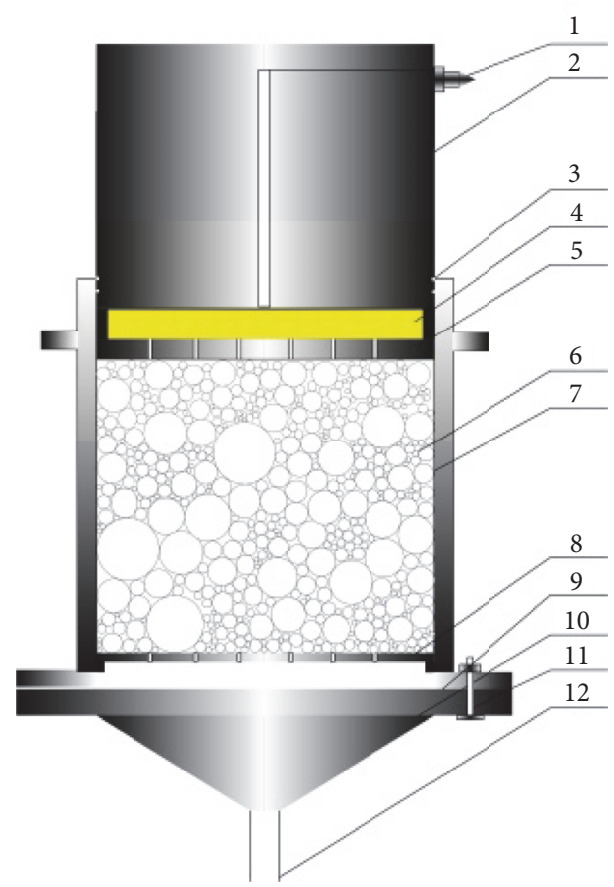

FIGURE 8: Detailed design of the seepage testing apparatus. Notes. 1-quick coupling for water inlet, 2-piston, 3,9-O-shaped rubber seal rings, 4-Aeolian sand, 5-sand storage tank, 6-specimen of granular rock mass, 7-cylinder cell, 8 -felt filtration chest, 10-base plate, 11screw, and 12-water outlet.

TABLE 3: Scheme for seepage tests without sand.

\begin{tabular}{lccc}
\hline Test number & Size distribution parameter $n$ & $h / \mathrm{mm}$ & $\varphi$ \\
\hline$(1)$ & 0.50 & 147 & $21.7 \%$ \\
$(2)$ & 0.75 & 147 & $21.7 \%$ \\
$(3)$ & 1.00 & 147 & $21.7 \%$ \\
$(4)$ & 1.25 & 147 & $21.7 \%$ \\
$(5)$ & 1.50 & 147 & $21.7 \%$ \\
$(6)$ & 1.00 & 142 & $19.0 \%$ \\
$(7)$ & 1.00 & 137 & $16.0 \%$ \\
$(8)$ & 1.00 & 132 & $12.9 \%$ \\
$(9)$ & 1.00 & 127 & $9.4 \%$ \\
$(10)$ & 1.00 & 125 & $8.2 \%$ \\
$(11)$ & 1.50 & 142 & $19.0 \%$ \\
$(12)$ & 1.50 & 137 & $16.0 \%$ \\
$(13)$ & 1.50 & 132 & $12.9 \%$ \\
$(14)$ & 1.50 & 127 & $9.4 \%$ \\
$(15)$ & 1.50 & 125 & $8.2 \%$ \\
\hline
\end{tabular}

mainly due to the rearrangement of the pore structure. For simplification, the particle breaking during the compression was not considered in present study.

Based on the height $h$, the porosity of each specimen can be calculated as follows:

$$
\varphi=1-\frac{m}{\rho Q h}
$$

TABLE 4: Scheme for sand inrush tests in granular sandstone.

\begin{tabular}{lccccccc}
\hline$\varphi$ & $7.9 \%$ & $8.5 \%$ & $9.2 \%$ & $10.4 \%$ & $11.6 \%$ & $12.8 \%$ & $13.4 \%$ \\
\hline$n=0.9$ & & & & & $\sqrt{ }$ & $\sqrt{ }$ & $\sqrt{ }$ \\
$n=1.0$ & & & & $\sqrt{ }$ & $\sqrt{ }$ & $\sqrt{ }$ & \\
$n=1.1$ & $\sqrt{ }$ & $\sqrt{ }$ & $\sqrt{ }$ & $\sqrt{ }$ & & & \\
$n=1.2$ & $\sqrt{ }$ & $\sqrt{ }$ & $\sqrt{ }$ & $\sqrt{ }$ & & & \\
$n=1.3$ & $\sqrt{ }$ & $\sqrt{ }$ & $\sqrt{ }$ & $\sqrt{ }$ & & & \\
\hline
\end{tabular}

where $\varphi$ is the porosity, $m$ is the mass of the sample, $\rho$ is density of the rock particle, and $Q$ is the cross section area of the cylinder cell. The calculated values of the porosity are also listed in Table 3.

The procedure for the seepage test is as follows.

Step 1. The rock particles of different sizes were assembled according to the size distribution parameter $n$. Then, we mixed them as homogeneously as possible and put them in the cylinder cell of seepage testing apparatus until the height of the specimen was $150 \mathrm{~mm}$. The actual height of the specimen might have a slight deviation from $150 \mathrm{~mm}$ due to the uneven surface.

Step 2. We compressed the specimen to the specific height $h$ using the MTS816 via displacement control mode.

Step 3. The pump was connected to the seepage testing apparatus, with an inlet water pressure of $0.5 \mathrm{MPa}$.

Step 4. The water from the outlet was collected and weighted during the test.

2.3.2. Sand Inrush Test in Granular Rock Mass. In this test, the aeolian sand was put in the storage tank over the specimen of granular rock mass (Figure 8). According to the seepage test mentioned above, we can analyze the permeability of the granular rock mass under different conditions. However, we are still not sure whether sand will move through the granular rock mass under certain conditions. Thus, we first started the sand inrush tests with high values of the porosity and size distribution parameter $(n)$. Then, we decreased their values gradually. When the amount of the sand from the outlet changes greatly in a specific condition, it means that the sand inrush occurs. The whole experimental scheme is presented in Table 4. The experimental conditions include two factors, that is, the porosity $\varphi$ and particle-size distribution parameter $n$. The tests under conditions with tick in Table 4 were performed. Specifically, we first carried out the test with the porosity $\varphi$ of $13.4 \%$ when the particle-size distribution parameter $n$ was 0.9 . We found that a lot of sand moved out from the outlet. Then, the tests with porosity of $12.8 \%$ and $11.6 \%$ were conducted, and only a small amount of sand was collected from the outlet. Thus, it is inferred that the sand inrush starts to happen when $n$ is 0.9 and $\varphi$ is $13.4 \%$. For the cases with the porosity $\varphi$ smaller than $11.6 \%$, sand inrush will not happen when $n$ is 0.9 . Therefore, these cases were not performed. 


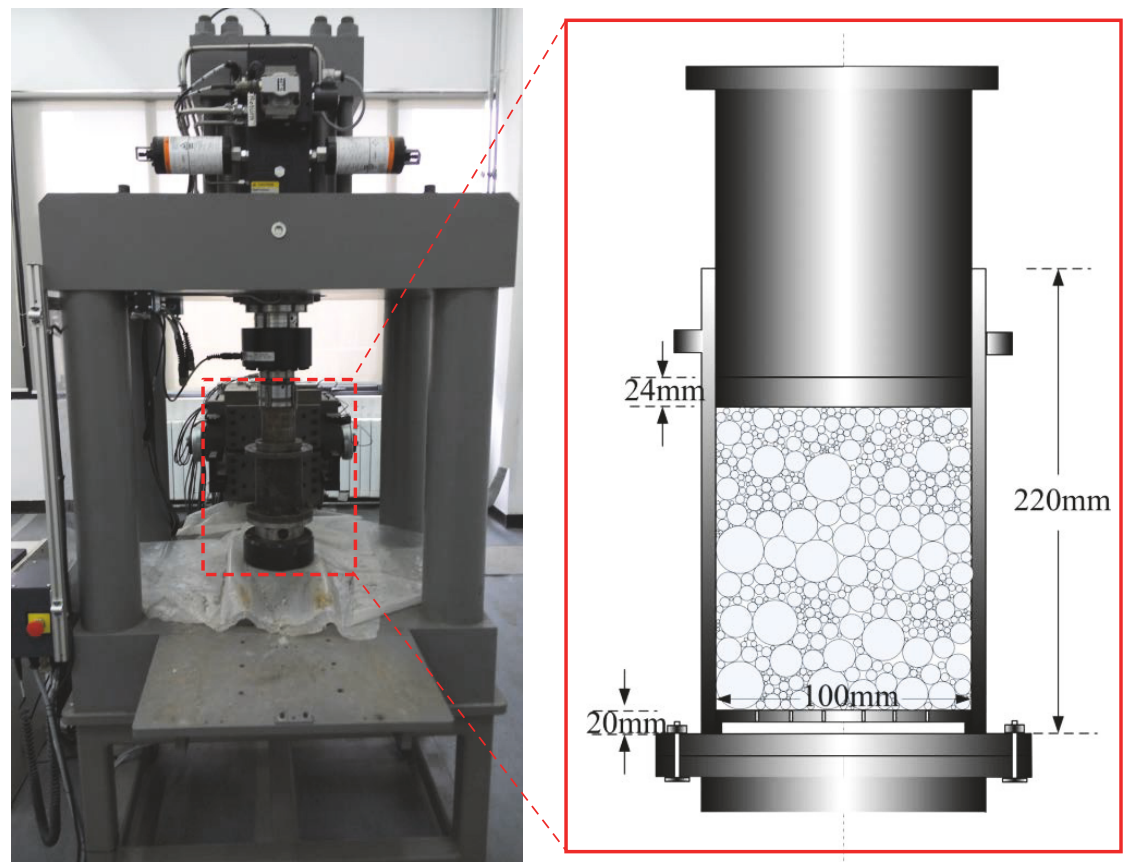

FIGURE 9: Layout of the testing system: an MTS816 servo-control testing machine and a seepage testing apparatus.

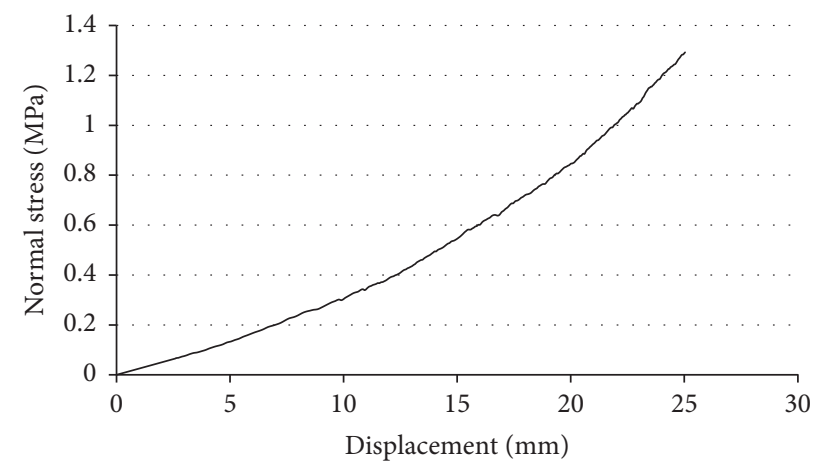

FIGURE 10: Compressive curve of the specimen with $n$ of 1.5 and $\varphi$ of $8.2 \%$.

The procedure for the sand inrush test is as follows.

Step 1. Assemble the rock particles of different sizes according to the size distribution parameter $n$, and put them in the cylinder cell of seepage testing apparatus until the height of the specimen is $150 \mathrm{~mm}$.

Step 2. Compress the specimen to the specific height $h$ using the MTS816 via the displacement control mode.

Step 3. Put the aeolian sand in the storage tank. In each sample, the amount of sand was constant, that is, $500 \mathrm{~g}$.

Step 4. Compress the piston of the seepage testing apparatus again to make the height of the specimen equal to the specific value in Step 2.

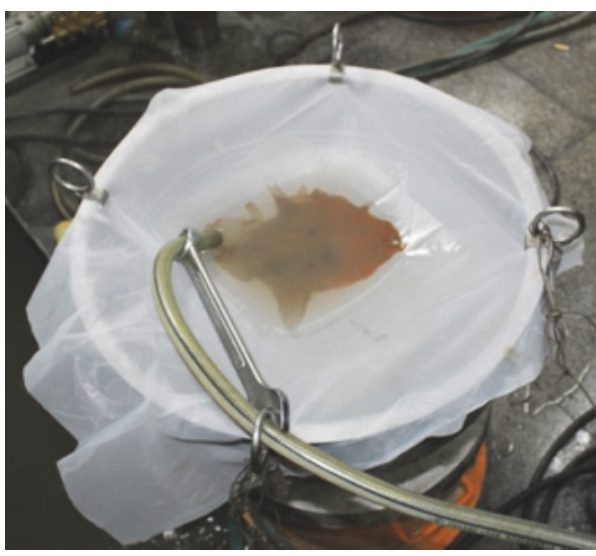

FIGURE 11: Collection of the aeolian sand using a 200-mesh strainer.

Step 5. Connect the pump to the seepage testing apparatus and keep the inlet water pressure at $0.5 \mathrm{MPa}$.

Step 6. Collect the aeolian sand using a 200-mesh strainer (Figure 11). Then, the collected sand was dried and the mass of the sand was weighed.

\section{Theory Basis}

Darcy's law is adopted here to analyze the permeability and seepage velocity. The seepage velocity can be expressed as

$$
v=\frac{k}{\mu} \nabla p,
$$




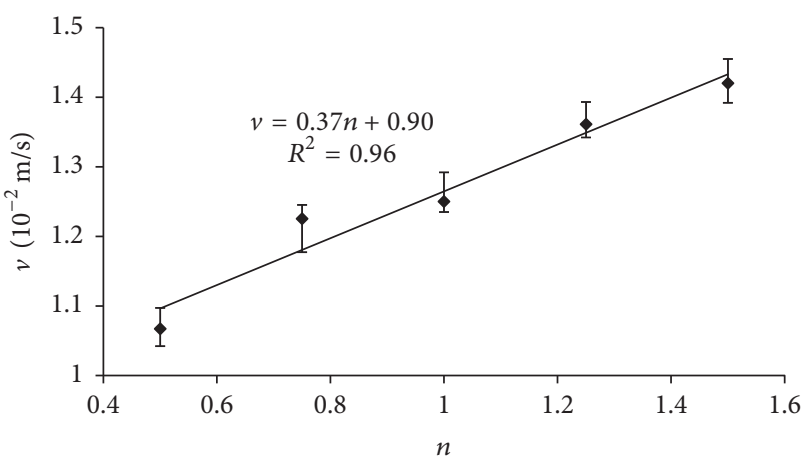

FIGURE 12: Seepage velocity versus particle-size distribution parameter $(\varphi=21.7 \%)$.

where $v$ is the seepage velocity, $\mathrm{m} / \mathrm{s}$; $k$ is the permeability of the specimen, $\mathrm{m}^{2} ; \mu$ is the dynamic viscosity of the fluid, Pa.s; and $\nabla p$ is the pressure gradient, $\mathrm{Pa} / \mathrm{m}$.

In the experiments, the pressure gradient $\nabla p$ and dynamic viscosity of the fluid $\mu$ are both constant. Then, the seepage velocity $v$ is linear to the permeability $k$. As the permeability $k$ is an intrinsic property of the specimen, which is related to the pore structure of granular rock mass, the seepage velocity $v$ should be the function of particle-size distribution parameter $n$ and the porosity $\varphi$ :

$$
v=f(n, \varphi) .
$$

Based on the results of the seepage test, the function in (4) can be determined.

\section{Results and Discussion}

4.1. Seepage Property of Granular Rock Mass. According to the experimental scheme in Table 3, we obtain the seepage velocity under different conditions with various particle-size distribution parameters and porosity values. The relationship between the seepage velocity and parameter $n$ is shown in Figure 12. It is clear that there is a linear proportional relationship between the velocity $v$ and the parameter $n$. In Figure 12, the error is also exhibited based on the three testing results in each test. It is found that the seepage in the granular rock mass has a high deviation; however, a general relationship between the seepage velocity and the parameter $n$ is still demonstrated.

The relation between the seepage velocity and porosity is shown in Figure 13. When the porosities increase from $8 \%$ to $22 \%$, the relationship between the seepage velocity and the porosity was almost linear.

From the above analysis, we may conclude that the seepage velocity can be predicted based on linear relationship between $n$ and $\varphi$ in the present range of $n$ and $\varphi$. From Figure 12, the relation between the seepage velocity of parameter $n$ can be proposed based on the fitted equation $(\varphi=21.7 \%)$ :

$$
v=\left.\left(0.56 \frac{n}{n_{0}}+0.90\right)\right|_{\varphi=21.7 \%},
$$

where $v$ is the predicted seepage velocity; $n_{0}$ is the reference value $\left(n_{0}=1.5\right)$ for the particle-size distribution parameter.

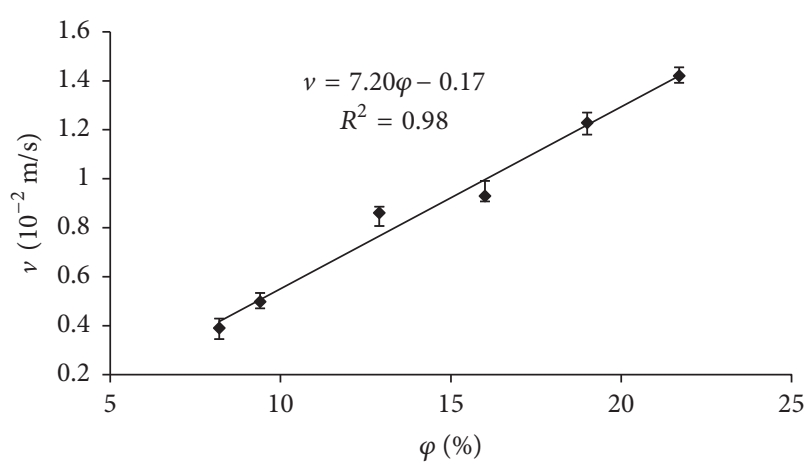

FIGURE 13: Seepage velocity versus porosity $(n=1.5)$.

From Figure 13, the relation between the seepage velocity of porosity $\varphi$ can be proposed based on the fitted equation $(n=1.5)$ :

$$
v=\left.\left(1.56 \frac{\varphi}{\varphi_{0}}-0.17\right)\right|_{n=1.5},
$$

where $\varphi_{0}$ is the reference value for the porosity, which is $21.7 \%$ for granular rock mass.

Then, the linear relationship between seepage velocity and $n$ and $\varphi$ can be proposed as follows:

$$
v=\frac{\left(0.56\left(n / n_{0}\right)+0.90\right) \cdot\left(1.56\left(\varphi / \varphi_{0}\right)-0.17\right)}{v_{0}},
$$

where $v_{0}$ is the seepage velocity for the case $n=n_{0}$ and $\varphi=\varphi_{0}$, which is $0.0142 \mathrm{~m} / \mathrm{s}$.

Based on (7), the seepage velocity can be calculated for other cases. Figure 14 shows the comparison between the calculated and experimental seepage velocities for the case of $n=1.0$. In the figure, the experimental results are from the tests numbers (3) and (6) to (10) in Table 3. It can be seen that the proposed (7) can accurately predict the seepage velocity according to the corresponding porosity. However, it should be pointed out that (7) is only valid in the ranges of parameter $n$ and porosity $\varphi$ in the present experiment.

Based on (3) and (7), the permeability of the granular sandstone can be evaluated. The results show that the permeability ranges from $1.5 e^{-12}$ to $4.3 e^{-12} \mathrm{~m}^{2}$, which are consistent with the results of other researchers [15]. In Feng et al.'s work [15], the granular rock mass is made of red sandstone, and the parameter $n$ is from 0.3 to 0.9 .

4.2. Sand Inrush Criterion for Granular Rock Mass. An important characteristic of seepage in granular rock mass is that the permeability may vary with time due to the loss of small particles [15]. The structure of the rock mass changes gradually if the seepage time is too long, which makes it difficult to describe the conditions of the rock mass. After some trial of the sand inrush tests, it is found that sand inrush usually happens during the first minute of the test. Therefore, the seepage time in each test was limited to $1 \mathrm{~min}$. The mass of the collected sand in the sand inrush testing is listed in Table 5. We can see that the amount of the collected sand arise 


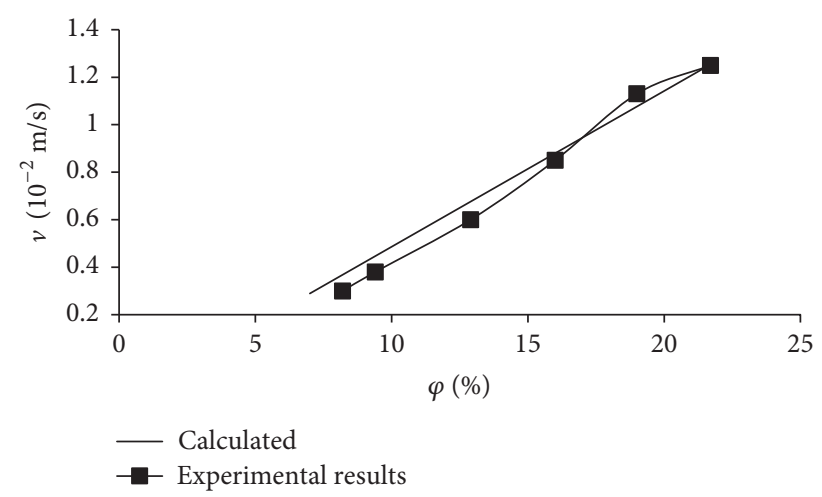

Figure 14: Comparison between the calculated and experimental seepage velocities $(n=1.0)$.

TABLE 5: Mass of collected sand from the outlet.

\begin{tabular}{lccccccc}
\hline$\varphi$ & $7.9 \%$ & $8.5 \%$ & $9.2 \%$ & $10.4 \%$ & $11.6 \%$ & $12.8 \%$ & $13.4 \%$ \\
\hline$n=0.9$ & $/$ & $/$ & $/$ & $/$ & $27.1 \mathrm{~g}$ & $42.5 \mathrm{~g}$ & $262.7 \mathrm{~g}$ \\
$n=1.0$ & $/$ & $/$ & $/$ & $1.9 \mathrm{~g}$ & $91.7 \mathrm{~g}$ & $226.5 \mathrm{~g}$ & $/$ \\
$n=1.1$ & $28.1 \mathrm{~g}$ & $28.5 \mathrm{~g}$ & $148.1 \mathrm{~g}$ & $172.5 \mathrm{~g}$ & $/$ & $/$ & $/$ \\
$n=1.2$ & $26.9 \mathrm{~g}$ & $242.9 \mathrm{~g}$ & $175.8 \mathrm{~g}$ & $270.8 \mathrm{~g}$ & $/$ & $/$ & $/$ \\
$n=1.3$ & $56.2 \mathrm{~g}$ & 139.0 & $348.0 \mathrm{~g}$ & $327.1 \mathrm{~g}$ & $/$ & $/$ & $/$ \\
\hline
\end{tabular}

with the increase in the porosity $\varphi$ and parameter $n$. In some cases, little sand could be collected from the outlet and sand inrush did not happen (e.g., $n=0.9$ and $\varphi<11.6 \%$ ).

To propose a criterion for sand inrush in granular sandstone, we assume that sand inrush occurred when the mass of the collected sand was more than $50 \mathrm{~g}$ (ten percent of the initial amount of the sand). Then, the critical conditions for sand inrush are achieved (see Table 6 and Figure 15). From Figure 15, it is found that the sand inrush zone could be clearly distinguished according to the values of porosity and particlesize distribution parameter. As the parameter $n$ increases, sand inrush will occur at lower porosity. It can be explained that the pore size becomes more inhomogeneous when the parameter $n$ and the ratio of large particles increase. Then, sand can move easily through the large and connected pores.

Based on (7) and Table 6, we can calculate the critical seepage velocity for sand inrush. As shown in Figure 16, it can be seen that the critical seepage velocity decreases quickly when the value of $n$ increases. When $n$ is higher than 1.1, the critical seepage velocity seems to vary slightly around $0.008 \mathrm{~m} / \mathrm{s}$. In situ, the rock particles may be very large (e.g., the rock blocks around the longwall mining face), which corresponds to a large value of the particle-size distribution parameter. Thus, sand inrush inevitably occurs even though the flow rate is very low if no prevention measures are adopted.

4.3. Prediction and Prevention of Sand Inrush during Coal Mining. Water and sand inrush is one of the most serious threats in some shallow coal mines in China. In the field, there are mainly two kinds of water and sand inrush problems. The first one is water and sand inrush through the boreholes drilled from the ground due to sealing problem. The other

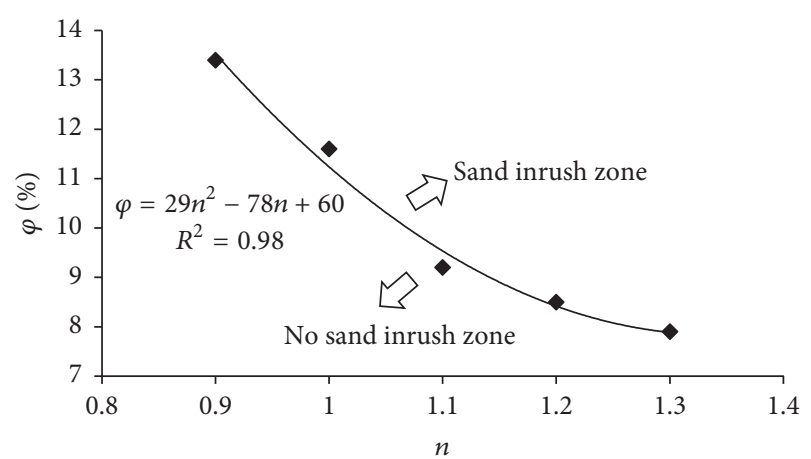

FIGURE 15: Criterion for sand inrush.

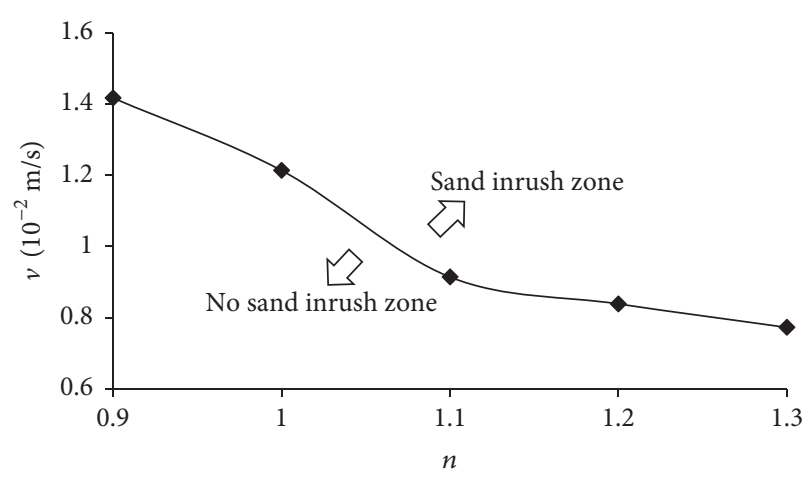

FIGURE 16: Critical seepage velocity for sand inrush under different particle-size distributions.

TABLE 6: Critical conditions for sand inrush.

\begin{tabular}{cccccc}
\hline$n$ & 0.9 & 1.0 & 1.1 & 1.2 & 1.3 \\
\hline$\varphi$ & $13.4 \%$ & $11.6 \%$ & $9.2 \%$ & $8.5 \%$ & $7.9 \%$ \\
\hline
\end{tabular}

one happens due to the mining induced fractures. According to the above conclusion, some principles should be adopted, such as reduction of the porosity, optimization of the pore structure of the granular rock mass, and reduction of the flow rate. More details and discussions are as follows.

4.3.1. Water and Sand Inrush through Boreholes. As the water can flow freely through the boreholes, it is difficult to predict the water and sand inrush in this case. The accident usually occurs quickly. For example, the rate of sand inrush was approximately $3270 \mathrm{~m}^{3} / \mathrm{h}$ in the water and sand inrush accident occurred at Longde coal mine through a borehole. Before the accident, the borehole had not been drilled through the rock layers over the mining face, and no sign was found at the drill site or underground.

In order to stop the sand inrush through the borehole, we should reduce the flow rate by filling the borehole with granular rock mass. Take the accident in Longde coal mine for an example. First, large rock blocks were threw into the borehole. Following that, small rock particles were pushed into the borehole, which reduced the particle-size distribution parameter of the granular rock mass in the borehole. After a period, the flow rate of water and sand decreased a 
lot. Then, cement paste was pumped into the granular rock mass in order to reduce the porosity of the granular rock mass in the borehole. After taking these measures, the flow rate of water reduced greatly and sand inrush stopped.

\subsubsection{Water and Sand Inrush through Mining Induced Frac-}

tures. When mining in shallow coal mines, the mining induced fractures may go through the rock layers and connect the aquifer and sand bed. When water flow transports through the mining induced fracture and permeates into the granular rock mass over the mined coal, the properties of the fractures and granular rock mass have a certain influence on the sand movement. The sand inrush can be predicted by monitoring water flow rate. As shown in the experiments, the possibility of sand inrush is low if the water flow rate is low and little sand is found in the flow. However, if the monitored water flow rate increases gradually during the mining, measures should be taken to prevent water and sand inrush accident.

There are several methods to control the water and sand inrush from the roof during the mining. The first is to decrease the water level in the aquifer via boreholes before mining. Meanwhile, we can reduce the porosity of the fractured zone over the mining face by filling the fractures with pressured cement paste. These measures can decrease the flow rate and reduce the risk of sand inrush. This method has been used in Halagou coal mine, which is located at the border of Shaanxi province [3]. Finally, the risk of sand inrush was eliminated successfully.

The second method is to control the failure of the rock mass in the roof by using backfilling mining method [20]. The goaf is filled with granular rock mass or paste, and the height of the fractures in the roof is under control. However, the water in the aquifer may still seep into the goaf around the faults or collapse columns, so does the sand. Therefore, the granular composition of the backfilling rock mass should be well designed, and the granular rock mass should be compressed to reduce the porosity to be as small as possible [21].

It should be pointed out that the present study is only a primary attempt to understand the water and sand inrush through the rock mass. The results are more or less a phenomenological description of the problem in granular rock mass, rather than a precisely quantitative comparison with the in situ measurements. Moreover, the characteristic of seepage through the granular rock mass in the field may be different from what we get in the laboratory due to the size effect.

\section{Conclusions}

(1) Talbot formula can be utilized to express the granular composition. The particle-size distribution parameter and the porosity are the two key properties of the granular rock mass.

(2) In current study, the seepage velocity has a linear relationship with the particle-size distribution parameter and porosity. The proposed equation can predict the seepage velocity very well when the parameters are within the specific range used in the tests.
(3) Based on the values of porosity and particle-size distribution parameter, the sand inrush zone can be clearly distinguished. As the parameter $n$ increases, the sand inrush will occur at lower porosity. At the same time, the sand inrush can also be estimated using the seepage velocity. When the parameter $n$ increases, the critical seepage velocity for sand inrush decreases quickly.

(4) According to the findings from the experiments, the principles for preventing water and sand inrush are reducing the porosity, optimizing the pore structure of the granular rock mass, and lowering the flow rate. In practice, the porosity can be reduced by compressing the granular rock mass or by grouting using cement paste. The pore structure can be improved by increasing the ratio of small rock particles. Additionally, the flow rate can be decreased by predraining water in the aquifer before mining. The proposed principles have been successfully used in-site to control the water and sand inrush.

\section{Conflicts of Interest}

The authors declare no conflicts of interest.

\section{Authors' Contributions}

Kai Zhang proposed the experimental plan and wrote the paper. Boyang Zhang and Jiangfeng Liu conducted the experiments. Dan Ma analyzed the data. Haibo Bai proposed the principles for preventing the water and sand inrush.

\section{Acknowledgments}

The authors acknowledge financial support by the Fundamental Research Funds for the Central Universities (2015QNA60) and the Natural Science Foundation of Jiangsu Province of China (BK20160249).

\section{References}

[1] X. Miao, X. Cui, J. Wang, and J. Xu, "The height of fractured water-conducting zone in undermined rock strata," Engineering Geology, vol. 120, no. 1-4, pp. 32-39, 2011.

[2] T. Liu, Surface Movements, Overburden Failure and Its Application, Coal Industry Press, Beijing, China, 1981.

[3] Y. Song, "Water inrush and sand inrush mechanism and prevention technology during the initial mining period in 22402 working face of Halagou coal mine," Mining Safety, vol. 43, no. 12, pp. 91-93, 2012.

[4] G. Zhang, K. Zhang, L. Wang, and Y. Wu, "Mechanism of water inrush and quicksand movement induced by a borehole and measures for prevention and remediation," Bulletin of Engineering Geology and the Environment, vol. 74, no. 4, pp. 13951405, 2015.

[5] A.-P. Tang, Y. Dong, Z.-D. Tan, and A.-H. Wen, "Mechanism of sandy-silt seepage deformation in mine under vibration," Earthquake Engineering and Engineering Vibration, vol. 19, no. 2, pp. 132-135, 1999. 
[6] M. Zhang, L. Zhang, X. Jiang, F. Liu, and G. Zhang, "Study on the inrushing mechanism of weak cemented quicksand layer and its forecasting," Metal Mine, no. 10, pp. 48-50, 2002.

[7] R. Medina, J. E. Elkhoury, J. P. Morris, R. Prioul, J. Desroches, and R. L. Detwiler, "Flow of concentrated suspensions through fractures: Small variations in solid concentration cause significant in-plane velocity variations," Geofluids, vol. 15, no. 1-2, pp. 24-36, 2015.

[8] Z. Jie, J. Z. Hou, and M. A. Li, "Sand inrush in roof rock's rotating in shallow seam mining," Journal of Xian University of Science and Technology, vol. 26, no. 2, pp. 158-160, 2006.

[9] W. Sui, G. Cai, and Q. Dong, "Experimental research on critical percolation gradient of quicksand across overburden fissures due to coal mining near unconsolidated soil layers," Chinese Journal of Rock Mechanics and Engineering, vol. 26, no. 10, pp. 2084-2091, 2007.

[10] E. Luijendijk and T. Gleeson, "How well can we predict permeability in sedimentary basins? Deriving and evaluating porositypermeability equations for noncemented sand and clay mixtures," Geofluids, vol. 15, no. 1-2, pp. 67-83, 2015.

[11] W. Yan, C. Chiu, and K. Yuen, "Prediction and modeling of permeability function and its application to the evaluation of breakthrough suction of a two-layer capillary barrier," Canadian Geotechnical Journal, vol. 54, no. 6, pp. 778-788, 2017.

[12] V. A. Torrealba, Z. T. Karpyn, H. Yoon, K. A. Klise, and D. Crandall, "Pore-scale investigation on stress-dependent characteristics of granular packs and the impact of pore deformation on fluid distribution," Geofluids, vol. 16, no. 1, pp. 198-207, 2016.

[13] D. Ma, X. Miao, H. Bai et al., "Impact of particle transfer on flow properties of crushed mudstones," Environmental Earth Sciences, vol. 75, no. 7, article 593, 2016.

[14] D. Ma, X. Miao, Y. Wu et al., "Seepage properties of crushed coal particles," Journal of Petroleum Science \& Engineering, vol. 146, pp. 297-307, 2016.

[15] M. Feng, J. Wu, and D. Ma, "Experimental investigation on the seepage property of saturated broken red sandstone of continuous gradation," Bulletin of Engineering Geology \& the Environment, pp. 1-12, 2017.

[16] S. Peng, Surface Subsidence Engineering, Society for Mining Metallurgy and Exploration, London, UK, 1992.

[17] N. A. Talbot and F. E. Richart, The Strength of Concrete, Its Relation to The Cement Aggregates and Water, vol. 137, Engineering Experiment station, University of Illinois, Urbana, Ill, USA, 1923.

[18] W. Fuller B and E. Thompson S, "The laws of proportioning concrete," Transactions of the American Society of Civil Engineers, vol. 59, pp. 67-143, 1907.

[19] D. Ma, X. X. Miao, G. H. Jiang, H. B. Bai, and Z. Q. Chen, "An experimental investigation of permeability measurement of water flow in crushed rocks," Transport in Porous Media, vol. 105, no. 3, pp. 571-595, 2014.

[20] Y. Huang, J. Li, T. Song, G. Kong, and M. Li, "Analysis on filling ratio and shield supporting pressure for overburden movement control in coal mining with compacted backfilling," Energies, vol. 10, no. 1, article no. 31, 2017.

[21] J. X. Zhang, X. J. Deng, X. Zhao, F. Ju, and B. Y. Li, "Effective control and performance measurement of solid waste backfill in coal mining," International Journal of Mining, Reclamation and Environment, vol. 31, no. 2, pp. 91-104, 2017. 

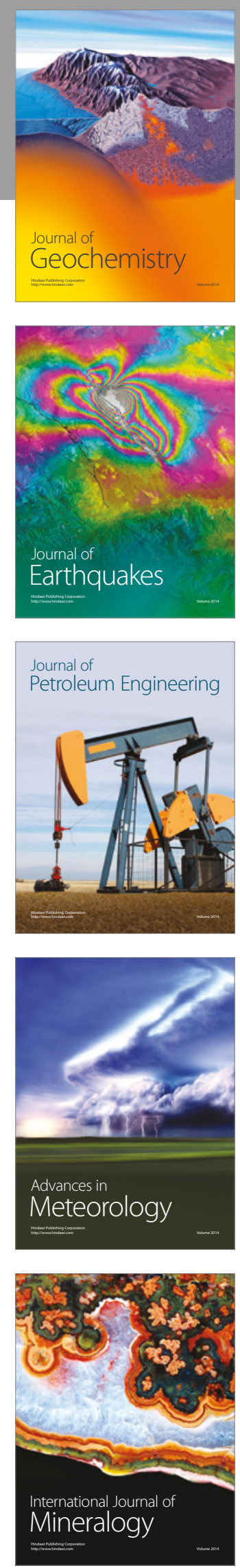
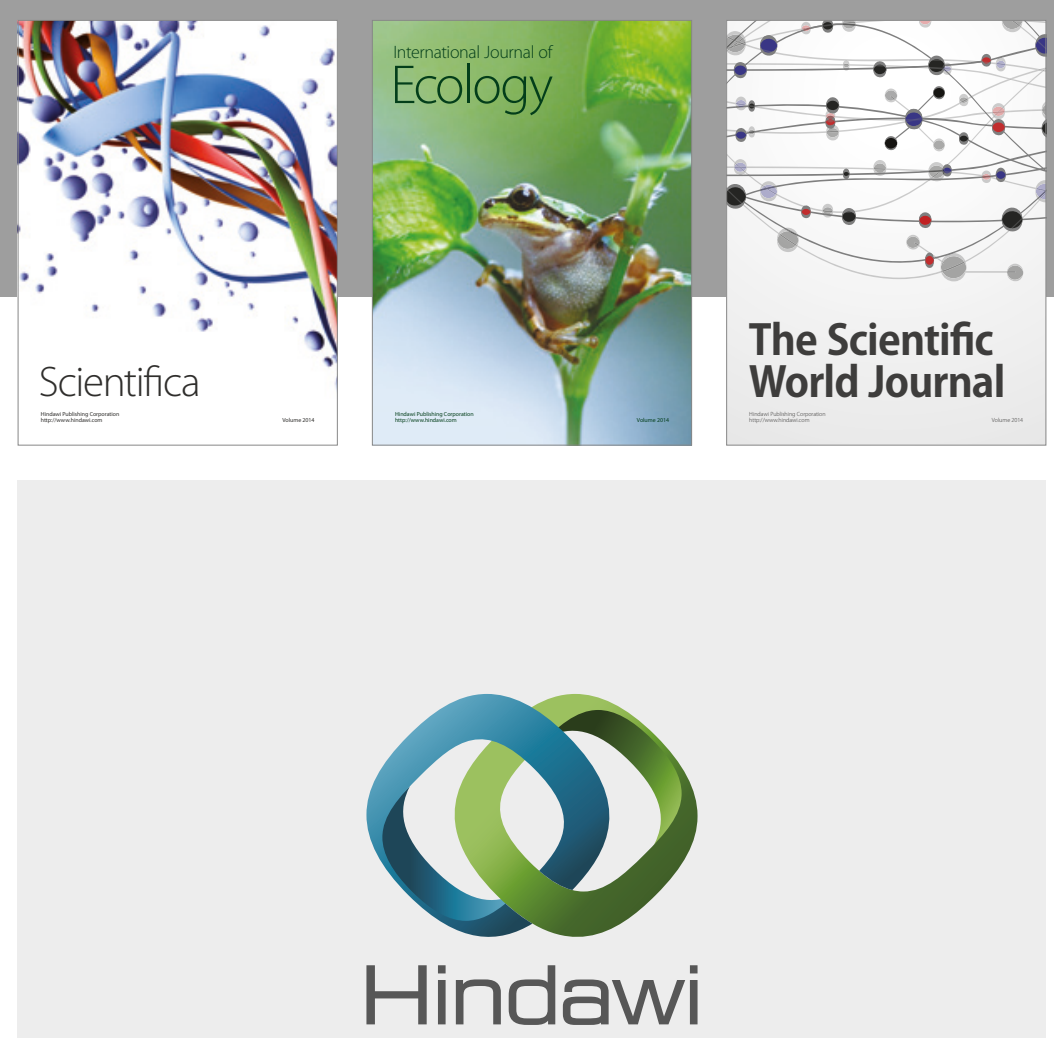

Submit your manuscripts at

https://www.hindawi.com
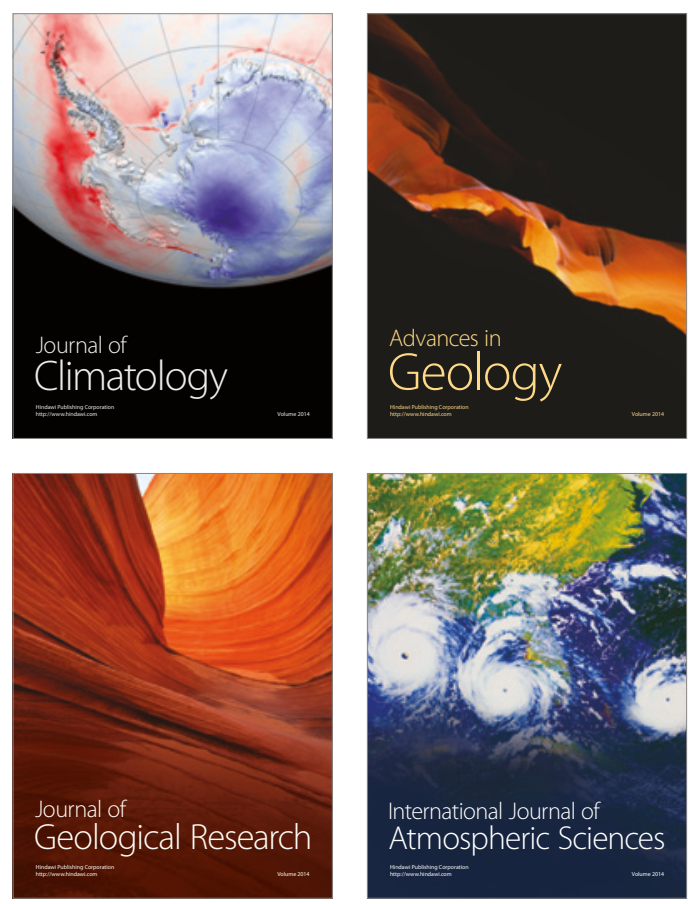

The Scientific

World Journal
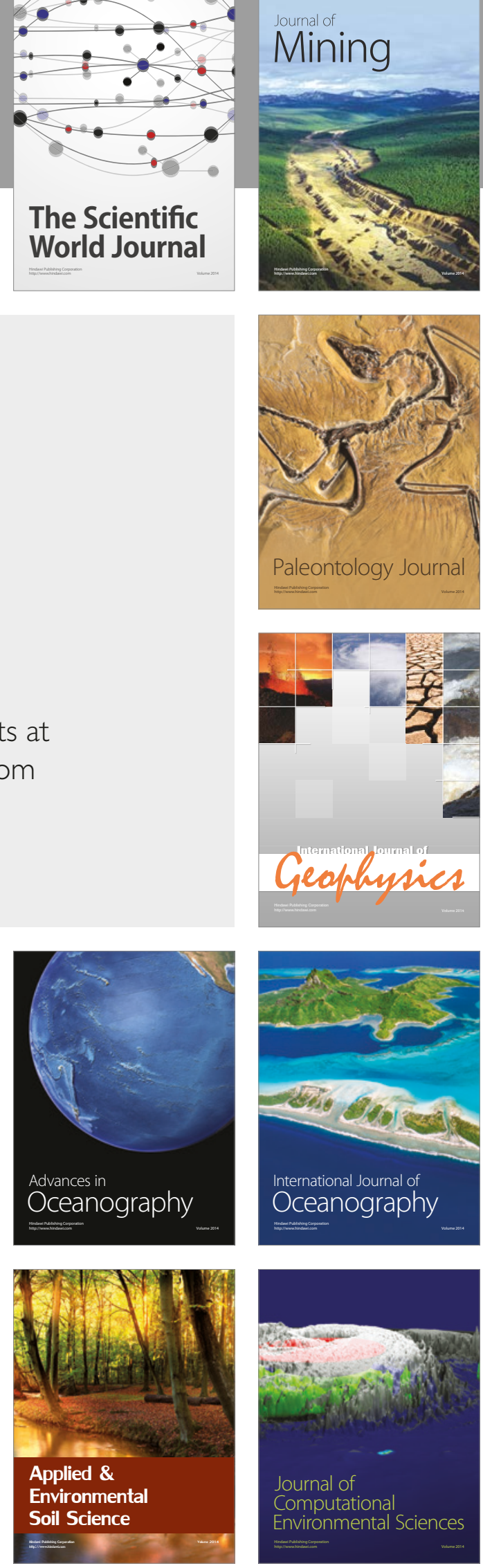